\title{
Early and Late Mortality of Spontaneous Hemorrhagic Transformation of Ischemic Stroke
}

\author{
Marco D'Amelio, $\mathrm{MD},{ }^{1}$ Valeria Terruso, $\mathrm{MD}, \mathrm{PhD},{ }^{1}$ Giorgia Famoso, MD, \\ Norma Di Benedetto, MD, Sabrina Realmuto, MD, Francesca Valentino, MD, \\ Paolo Ragonese, MD, PhD, Giovanni Savettieri, MD, and Paolo Aridon, MD, PhD
}

\begin{abstract}
Background: Hemorrhagic transformation (HT), a complication of ischemic stroke (IS), might influence patient's prognosis. Our aim is to evaluate, in a hospitalbased series of patients not treated with thrombolysis, the relationship between HT and mortality. Methods: We compared mortality of individuals with spontaneous HT with that of individuals without. Medical records of patients diagnosed with anterior IS were retrospectively reviewed. Outcome measures were 30- and 90-day survival after IS onset. Kaplan-Meier estimates were used to construct survival curves. Cox proportional hazards model was used to estimate hazard ratio (HR) for the main outcome measure (death). HT was stratified in hemorrhagic infarction and parenchymal hematoma $(\mathrm{PH})$. We also evaluated the relationship between HT and the main mortality risk factors (gender, age, premorbid status, severity of stroke, and radiological features). Results: Thirty days from stroke onset, $8.1 \%$ (19 of 233 ) of patients died. At multivariate analysis, PH (HR: 7.7, 95\% confidence interval [CI]: 2.1,27.8) and low level of consciousness at admission (HR: 5.0, 95\% CI: 1.3, 18.6) were significantly associated with death. At 3-month follow-up, mortality rate was $12.1 \%$ (28 of 232). At multivariate analysis, large infarct size (HR: 2.7, 95\% CI: 1.2, 6.0) and HT (HR: 2.3, 95\% CI: 1.0, 5.4) were independent risk factors for mortality. Parenchymal hematoma was, however, the strongest predictor of late mortality (HR: 7.9, 95\% CI: 2.9, 21.4). Conclusions: Neurological status and infarct size play a significant role, respectively, in early and late mortality after IS. Parenchymal hematoma independently predicts both early and late mortality. Key Words: Ischemic stroke-hemorrhagic transformationprognosis-survival-epidemiology.

(C) 2014 by National Stroke Association
\end{abstract}

\section{Introduction}

Hemorrhagic transformation (HT) is a common complication of ischemic stroke (IS). ${ }^{1}$ Overall stroke mortality has been widely studied. ${ }^{2}$ Thrombolytic therapy determines a significant reduction in the proportion of patients dead or dependent in activities of daily living. This bene- fit seems, however, to be compensated by an increase in deaths, with most of the excess of them occurring early and explained by intracranial hemorrhage. ${ }^{3}$ Most of the authors focused their interest on functional outcome of spontaneous $\mathrm{HT}^{4-6}$ and it is still uncertain how much spontaneous HT influences prognosis. ${ }^{7,8}$
From the Dipartimento di Biomedicina Sperimentale e Neuroscienze Cliniche, Università degli Studi di Palermo, Palermo, Italy.

Received January 8, 2013; revision received May 17, 2013; accepted June 5, 2013.

Funding: This work was supported by a grant from the University of Palermo (2007).

Disclosures: None.
Address correspondence to Marco D'Amelio, MD, Dipartimento di Biomedicina Sperimentale e Neuroscienze Cliniche, Università degli Studi di Palermo, Via Gaetano La Loggia 1, 90129 Palermo, Italy.

E-mail: marco.damelio@unipa.it.

1 These authors equally contributed to the article.

$1052-3057 / \$$ - see front matter

(C) 2014 by National Stroke Association

http://dx.doi.org/10.1016/j.jstrokecerebrovasdis.2013.06.005 
Table 1. Characteristics of patients by living status at 30 and 90 days from stroke onset

\begin{tabular}{|c|c|c|c|c|c|c|}
\hline & \multicolumn{3}{|c|}{$30 \mathrm{~d}$} & \multicolumn{3}{|c|}{$90 \mathrm{~d}$} \\
\hline & Alive $(n=214)$ & Dead $(n=19)$ & $P$ & Alive $(n=204)$ & $\operatorname{Dead}(n=19+9)$ & $P$ \\
\hline Age (mean $\pm \mathrm{SD})$ & $72.3 \pm 12.1$ & $77.2 \pm 8.5$ & NS & $72.1 \pm 12.2$ & $77.4 \pm 8.8$ & .03 \\
\hline Sex (male) & $112(52.3 \%)$ & $9(47.4 \%)$ & NS & $107(52.5 \%)$ & $13(46.4 \%)$ & NS \\
\hline Previous stroke & $68(31.8 \%)$ & $4(21 \%)$ & NS & $65(31.9 \%)$ & $7(25.0 \%)$ & NS \\
\hline Hypertension & $160(74.8 \%)$ & $12(63.1 \%)$ & NS & $153(75.0 \%)$ & $18(64.3 \%)$ & NS \\
\hline Diabetes & $79(36.9 \%)$ & $5(26.3 \%)$ & NS & $75(36.8 \%)$ & $8(28.6 \%)$ & NS \\
\hline Current smoking & $87(40.6 \%)$ & $9(47.4 \%)$ & NS & $84(41.2 \%)$ & $11(39.3 \%)$ & NS \\
\hline Cardioembolic stroke & $64(29.9 \%)$ & $8(42.1 \%)$ & NS & $60(29.4 \%)$ & $12(42.9 \%)$ & NS \\
\hline Severe consciousness impairment & $3(1.4 \%)$ & $4(21 \%)$ & $<.0001$ & $3(1.5 \%)$ & $4(14.3 \%)$ & .0002 \\
\hline Presence of early CT signs & $59(27.6 \%)$ & $10(52.6 \%)$ & .02 & $57(27.9 \%)$ & $12(42.9 \%)$ & NS \\
\hline Medium/large infarcts & $41(19.1 \%)$ & $9(47.4 \%)$ & .004 & $36(17.6 \%)$ & $13(46.4 \%)$ & .0005 \\
\hline $\mathrm{HT}(\mathrm{HI}+\mathrm{PH})$ & $23(10.7 \%)$ & $6(31.6 \%)$ & .008 & $20(9.8 \%)$ & $9(32.1 \%)$ & .0008 \\
\hline $\mathrm{HI}$ & $16(7.5 \%)$ & $3(15.8 \%)$ & NS & $15(7.4 \%)$ & $4(14.3 \%)$ & NS \\
\hline $\mathrm{PH}$ & $7(3.3 \%)$ & $3(15.8 \%)$ & .01 & $5(2.5 \%)$ & $5(17.9 \%)$ & .0002 \\
\hline
\end{tabular}

Abbreviations: CT, computed tomography; HI, hemorrhagic infarction; HT, hemorrhagic transformation; NS, not significant; PH, parenchymal hematoma.

\section{Aims}

The current retrospective cohort analysis was designed to analyze, in a hospital-based series of patients with IS not treated with recanalization therapy, the association between HT and mortality.

\section{Materials and Methods}

All consecutive patients with anterior IS admitted to our department in the period 2004-2006 were enrolled in this study. Inclusion criteria have been previously reported. 9,10 Briefly, all patients performed a baseline brain computed tomography (CT) scan within 24 hours from symptoms onset and a follow-up CT. Patients with transient ischemic attacks and cerebral hemorrhage were excluded. If living status was not determinable, patients were excluded from current analysis.

Early and late mortality were, respectively, defined as the proportion of patients who died within 30 days and 3 months after stroke onset. Data about mortality were obtained from the public record office of the municipality of Palermo or directly by telephone interview. HT was stratified in hemorrhagic infarction (HI) and parenchymal hematoma (PH). ${ }^{11,12} \mathrm{HI}$ was defined as a petechial infarction without space-occupying effect, and $\mathrm{PH}$ was defined as a hemorrhage with mass effect. ${ }^{8}$ Together with HT, the following risk factors for mortality were investigated: gender, age, smoking (ever-smokers versus nonsmokers), previous cerebrovascular accidents (transient ischemic attack, IS, or hemorrhagic stroke), hypertension, diabetes, cardioembolic origin of stroke (classified according to the Trial of Org 10172 in Acute Stroke Treatment criteria), ${ }^{13}$ impairment of consciousness at admission (moderate to severe versus normal to mild impairment), early CT signs (hyperdensity of middle cerebral artery, focal hy- podensity consistent with the clinical picture, swelling because of developing infarction, blurring of gray matter-white matter distinction), and infarct size (mediumlarge infarcts versus small ones). ${ }^{14}$

The study has been approved by the local ethics committee.

\section{Statistical Analysis}

Clinical characteristics of patients dead or alive at 30-day follow-up were compared using $\chi^{2}$ test for categorical variables and $t$ test for continuous variables. Kaplan-Meier estimates were used to construct survival curves for early and late mortality. Estimates were calculated including only those who were still alive at last follow-up or if dead, whose date of death was known. The statistical difference between groups was tested with the log-rank test. Odds ratios, calculated by Cox proportional hazards analysis, were used as measure of association of poor outcome and the variables investigated (age, gender, clinical characteristics on admission, risk factors for stroke, CT findings, and HT). Multivariate analysis included the variables found significantly associated with death in the univariate analysis. Statistical analysis was performed using SAS 9.2.

\section{Results}

During the study period, 240 patients were included in the study. All patients received, together with medical therapies required by concomitant diseases, acetylsalicylic acid and subcutaneous heparin at the dosage recommended to prevent deep venous thrombosis. Living status, 1 month after stroke onset, was available for 233 of the 240 patients initially included in the study $(97.1 \%)$, whereas at 3 months, 1 more patient was lost at 
A
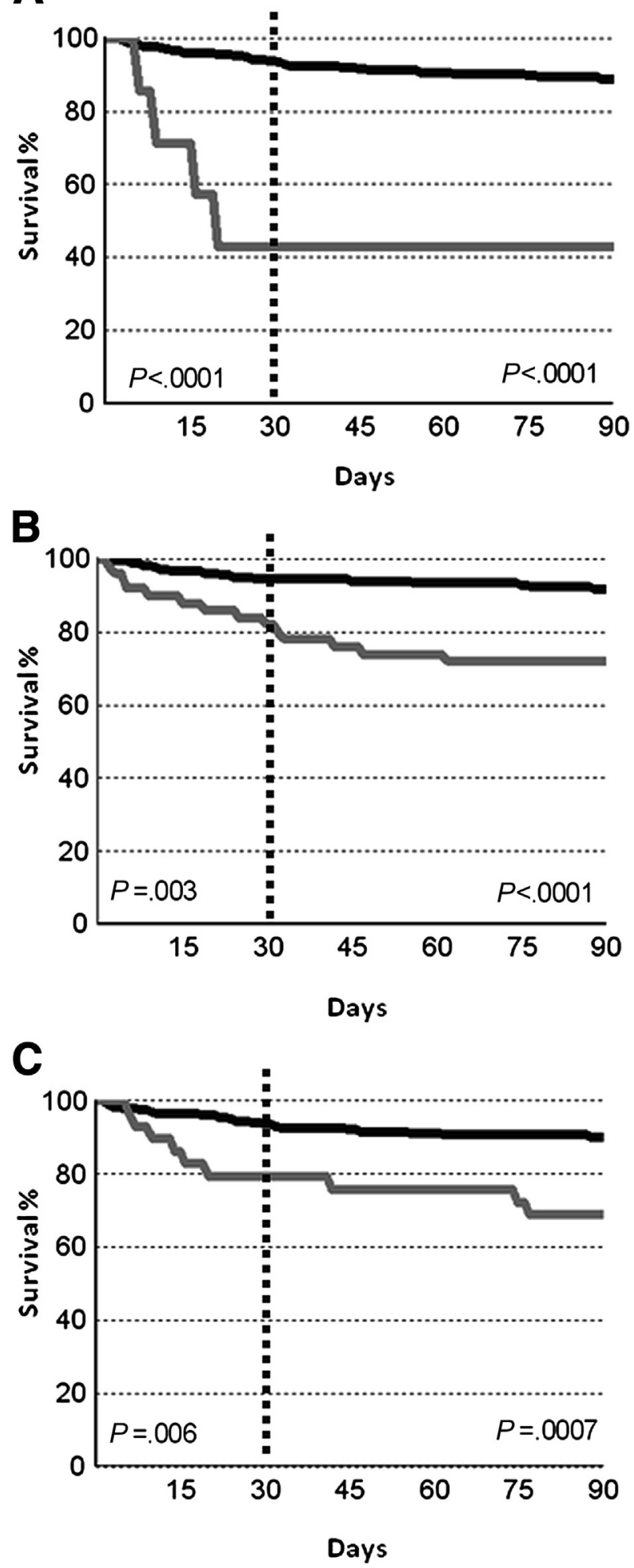

Figure 1. Cumulative survival probability of patients stratified by impairment of consciousness, lesion size, and HT. Cumulative survival probability stratified by $(A)$ impairment of consciousness (gray line = impairment of consciousness; black line = no impairment of consciousness); (B) lesion size (gray line = medium/large lesions; black line = small lesions); (C) HT (gray line $=H T ;$ black line $=$ no HT) $(\mathrm{P}$ values reported at the left of the vertical line refer to mortality at 30 days, whereas those at the right of the same line refer to mortality at 90 days). Abbreviation: HT, hemorrhagic transformation. follow-up (232 of 240, 96.7\%). HT did not occur in any of the 8 patients lost at follow-up. At 30 days from stroke onset, 19 of 233 patients died (8.1\%). No significant difference was observed for age at admission, gender, and stroke risk factors between patients who died and those who were still alive 30 days from stroke onset (Table 1). Patients who died, compared with those who survived, had a significantly more severe neurological status, larger lesions, and more frequently showed early CT signs at first neuroimaging or $\mathrm{HT}$ at a follow-up CT scan (Table 1). A highly significant difference between strata was observed when patients were stratified according to the presence of impairment of consciousness (log-rank test: $\chi^{2} 12.22$; df $\left.1 ; P<.0005\right)$, size of the lesions (logrank test: $\left.\chi^{2} 7.09 ; d f 1 ; P<.008\right)$, and the occurrence of HT (log-rank test: $\chi^{2} 5.56 ; d f 1 ; P<.02$ ) (Fig. 1). Death, at multivariate analysis, was significantly associated only with a more severe neurological deficit at admission (presence of consciousness impairment). When HT was stratified in $\mathrm{HI}$ and $\mathrm{PH}, \mathrm{HI}$ was not associated with an increased risk of early mortality, whereas $\mathrm{PH}$ was associated with an almost 8-fold increased risk of death (Table 2).

At 3-month follow-up, 9 more patients had died (28 of $232,12.1 \%$ ). At multivariate analysis, larger lesions and HT were independent risk factors for late mortality.

\section{Discussion}

In our study, overall mortality was of $8.1 \%$ at 1 month after stroke onset and $12.1 \%$ at 3-month follow-up. Only $\mathrm{PH}$ and impairment of consciousness were independently associated with an increased risk of mortality at 30 days. Ninety days after stroke onset, individuals with larger lesions or whose IS was complicated by the occurrence of HT had a significantly increased risk of death. Neurological status was still associated with death.

Data on outcome of patients with IS complicated by the occurrence of HT derive mostly from randomized trials looking at the efficacy of thrombolysis (Table 3). A recent analysis identified 16 trials separately reporting data, both in the treated and in the control group, on fatal intracranial hemorrhage occurring within 7-10 days from thrombolysis. ${ }^{3}$ Risk of death for intracranial hemorrhage was higher in treated patients $(4.45 \%)$ compared with controls $(.74 \%)$, so that most of the excess of early deaths in patients treated with thrombolysis were attributed to intracranial hemorrhage.

Thrombolysis, a proven instrument to reduce stroke severity, influences, in fact, several aspects of stroke especially the occurrence of HT.

Moreover, results of clinical trials may not be easily generalized as characteristics of enrolled participants might be different from patients not enrolled in clinical trial $^{15}$ and therefore, not representative of the general 
Table 2. Predictors of early and late mortality: results of univariate and multivariate analysis

\begin{tabular}{|c|c|c|c|c|c|c|c|c|}
\hline & \multicolumn{4}{|c|}{ 30-d mortality } & \multicolumn{4}{|c|}{ 90-d mortality } \\
\hline & HR (95\% CI) & $P$ & $\mathrm{HRa}(95 \% \mathrm{CI})$ & $P$ & HR $(95 \% \mathrm{CI})$ & $P$ & $\mathrm{HRa}(95 \% \mathrm{CI})$ & $P$ \\
\hline Age & $1.0(.99,1.10)$ & NS & $1.0(.97,1.1)$ & NS & $1.05(1.0,1.1)$ & .03 & $1.03(.99,1.1)$ & NS \\
\hline Gender (male) & $.8(.3,2.1)$ & NS & - & & $.8(.3,1.7)$ & NS & & \\
\hline Diabetes & $.6(.2,1.8)$ & NS & - & & $.7(.3,1.6)$ & NS & & \\
\hline Previous stroke & $.6(.2,1.8)$ & NS & - & & $.7(.3,1.8)$ & NS & & \\
\hline Hypertension & $.6(.2,1.5)$ & NS & - & & $.6(.3,1.4)$ & NS & & \\
\hline Cardioembolic stroke & $1.7(.7,4.2)$ & NS & - & & $1.4(.7,3.0)$ & NS & & \\
\hline $\begin{array}{l}\text { Severe consciousness } \\
\text { impairment }\end{array}$ & $12.0(3.9,36.3)$ & $<.0001$ & $5.0(1.3,18.8)$ & .01 & $8.2(2.8,23.6)$ & .0001 & $3.0(.9,9.9)$ & NS \\
\hline Presence of early CT signs & $2.7(1.1,6.8)$ & .03 & $1.8(.7,4.8)$ & NS & $1.8(.8,3.7)$ & NS & & \\
\hline Medium/large infarcts & $3.5(1.5,8.7)$ & .006 & $1.8(.6,5.5)$ & NS & $3.9(1.9,8.0)$ & .0003 & $2.7(1.2,6.0)$ & .02 \\
\hline $\mathrm{HT}(\mathrm{HI}+\mathrm{PH})$ & $3.5(1.3,9.3)$ & .01 & $1.8(.6,5.5)$ & NS & $3.6(1.6,7.9)$ & .002 & $2.3(1.0,5.4)$ & .05 \\
\hline No HT & Ref. & & Ref. & & Ref. & & Ref. & \\
\hline HI & $2.6(.7,9.1)$ & NS & $.8(.2,3.2)$ & NS & $2.3(.8,6.7)$ & NS & $1.0(.3,3.2)$ & NS \\
\hline $\mathrm{PH}$ & $5.6(1.6,19.8)$ & .007 & $7.7(2.1,27.8)$ & .002 & $6.6(2.5,17.6)$ & .0002 & $7.9(2.9,21.4)$ & $<.0001$ \\
\hline
\end{tabular}

Abbreviations: CT, computed tomography; CI, confidence interval; HI, hemorrhagic infarction; HR, hazard ratio; $\mathrm{HRa}, \mathrm{HI}$ and PH adjusted for impairment of consciousness, presence of early CT signs, and lesion size; HT, hemorrhagic transformation; NS, not significant; PH, parenchymal hematoma.

population, as on the contrary, it is advisable in epidemiological studies.

Interesting findings on outcome come also from stroke registries, where patients are included independently from specific characteristics and that often incorporate unbiased data coming both from academic and community hospitals and department of neurology and internal and geriatric medicine.

This is the case of the German Stroke Register Study Group (ADSR), ${ }^{16}$ a network of regional hospital-based stroke register, monitoring quality of stroke care in Germany. The analysis of the ADSR, aimed to investigate predictors of in-hospital mortality of patients treated with recombinant tissue plasminogen activator, found that the occurrence of symptomatic intracranial hemorrhage was the second most important complications of IS predicting early mortality. Patients with symptomatic intracranial hemorrhage had a significant 8-fold increased risk of death.

The Nationwide Inpatients Sample has been investigated for mortality risk for the years 1999-2002, ${ }^{17}$ comparing 2594 patients treated with thrombolysis with 246,370 patients not treated. Although intracerebral hemorrhage occurred in very small percentage of not treated patients $(.4 \%)$, in-hospital fatality rate for intracerebral hemorrhage in this group was $25 \%$.

Frequently, prognosis has been investigated pooling together data on functional outcome and death.

In a small sample of 53 patients with atrial fibrillation and nonlacunar stroke involving the vascular territory of the middle cerebral artery, ${ }^{4}$ at 3-month follow-up, severe disability (using a modified Rankin scale score $>2$ ) and death were not significantly asso- ciated with HT. However, in this series, HT was nearly 2 times more frequent in the group with worst outcome $(38 \%)$ compared with those with better outcome (21\%).

A larger hospital-based study, ${ }^{5}$ including all consecutive patients with IS, reported an overall mortality rate of $7.3 \%$ within 3 months after stroke onset. The authors reported a significant correlation between symptomatic HT (defined as HT on neuroimaging with any neurological deterioration) and poor outcome (death and Rankin scale score $>2$ ) at 3 months (odds ratio: $3.57,95 \%$ confidence interval: 1.33-9.54).

Similar results were observed in a multicenter prospective study enrolling 1125 patients with IS. ${ }^{18}$ Death or disability (modified Rankin scale score $\geq 3$ ) was seen in 33 of the 36 patients with $\mathrm{PH}(91.7 \%), 35$ of the 98 patients with HT $(57.4 \%)$ as compared with 387 of the remaining patients without HT (37.9\%). PH, but not HT overall, was significantly associated with an increased risk for death or disability (odds ratio: 15.3, 95\% confidence interval: 2.4, 99.4).

More recently, the prospective cohort of the Helsinki Stroke Thrombolysis Registry was investigated to assess the impact of symptomatic intracerebral hemorrhage. ${ }^{19}$ Patients with symptomatic intracerebral hemorrhage had a significant increased risk of fatal outcome that, according to the different definitions used, ranged from 1.5 to 4.8 .

In our sample, early and late mortality were related to $\mathrm{PH}$ independently from infarct size and neurological status at admission. Although it is predictable that HT of IS might influence early mortality, it is interesting to note that still 90 days from stroke onset, individuals who 
Table 3. Results from studies reporting data on mortality of hemorrhagic

\begin{tabular}{|c|c|c|c|c|}
\hline Reference & Patients & Treatment & Outcome & Results \\
\hline Toni et $\mathrm{al}^{7}$ & $\begin{array}{l}150 \text { Patients with } \\
\text { supratentorial IS }\end{array}$ & $\begin{array}{l}\text { No thrombolysis; antithrombotic/i.v. } \\
\text { heparin for stroke treatment }\end{array}$ & $\begin{array}{l}\text { By day } 30, \text { mortality rate was } 16.7 \% \text {, } \\
\text { whereas } 41.3 \% \text { of patients were } \\
\text { disabled }\end{array}$ & $\begin{array}{l}\text { HT was not related to bad 30-d outcome (OR: .76; } \\
\text { 95\% CI: .25-2.37) }\end{array}$ \\
\hline Fiorelli et al ${ }^{8}$ & $\begin{array}{l}609 \text { Patients from } \\
\text { ECASS I trial }\end{array}$ & $\begin{array}{l}307 \text { of } 609 \text { patients were treated } \\
\text { with recombinant tPA }\end{array}$ & $\begin{array}{l}\text { At } 3 \text {-month follow-up, } 18.4 \% \text { of } \\
\text { patients died and } 49.3 \% \text { were } \\
\text { disabled (RS score } \geq 1)\end{array}$ & $\begin{array}{l}\text { Only patients with } \mathrm{PH} 2 \text { had a strongly increased } \\
\text { risk of } 24 \text {-hour deterioration (OR: } 32.3,95 \% \\
\text { CI: } 13.4-77.7 \text { ) and 3-month death (OR: } 18.0 \text {, } \\
\text { 95\% CI: } 8.05-40.1 \text { ) }\end{array}$ \\
\hline Berger et $\mathrm{al}^{20}$ & $\begin{array}{l}790 \text { Patients from } \\
\text { ECASS II trial }\end{array}$ & $\begin{array}{l}\text { Intravenous thrombolysis ( } 406 \\
\text { patients) versus placebo ( } 384 \\
\text { patients) }\end{array}$ & $\begin{array}{l}\text { Assessment of HT type on clinical } \\
\text { outcome }\end{array}$ & $\begin{array}{l}\text { Only PH2 was associated with an increased risk } \\
\text { for deterioration at } 24 \text { hours after stroke onset } \\
\text { (OR: } 18 ; 95 \% \text { CI: } 6-56 \text { ) and for death at } 3 \text { months } \\
\text { (OR: } 11 ; 95 \% \text { CI: } 3.7-36 \text { ) }\end{array}$ \\
\hline Heuschmann $^{16}$ & $\begin{array}{l}1658 \text { IS patients from } \\
\text { the German Stroke } \\
\text { Registers Study Group }\end{array}$ & All patients were treated with tPA & $\begin{array}{l}\text { In-hospital mortality in patients } \\
\text { with acute IS }\end{array}$ & $\begin{array}{l}\text { ICH occurred in nearly } 30 \% \text { of patients who died, } \\
\text { compared with } 4.6 \% \text { of those who survived } \\
\text { (OR: } 8.3,95 \% \text { CI: } 5.0-13.8 \text { ) }\end{array}$ \\
\hline Hong et $\mathrm{al}^{4}$ & 1254 Patients with IS & Antithrombotic therapy & $\begin{array}{l}\text { Death within the } 3 \text {-month period of } \\
\text { follow-up occurred in } 91 \text { patients } \\
\text { (7.3\%). } 34.9 \% \text { of patients had } \\
\text { a poor outcome at } 3 \text { months } \\
\text { (RS score } 3-6)\end{array}$ & $\begin{array}{l}\text { Symptomatic HT was independently associated } \\
\text { with poor outcome (OR: } 3.57,95 \% \\
\text { CI: } 1.33-9.54)\end{array}$ \\
\hline Paciaroni et $\mathrm{al}^{18}$ & 1125 Patients with IS & $5.8 \%$ treated with recombinant tPA & $\begin{array}{l}\text { At } 3 \text { months, } 29.2 \% \text { of patients were } \\
\text { disabled (RS score }>2 \text { ) and } \\
11.5 \% \text { died }\end{array}$ & $\begin{array}{l}\text { PH, but not HT, was independently associated } \\
\text { with an increased risk for death or disability } \\
\text { (OR: } 15.29,95 \% \text { CI: } 2.35-99.35)\end{array}$ \\
\hline Goldstein et $\mathrm{al}^{21}$ & $\begin{array}{l}2362 \text { Patients with } \\
\text { acute IS (retrospective } \\
\text { analysis from database) }\end{array}$ & $\begin{array}{l}311 \text { Patients treated with intravenous } \\
\text { tPA, } 72 \text { patients treated with } \\
\text { intra-arterial thrombolysis }\end{array}$ & $\begin{array}{l}\text { Risk of symptomatic HT and } \\
\text { in-hospital mortality }\end{array}$ & $\begin{array}{l}\text { Symptomatic HT was an independent predictor of } \\
\text { in-hospital mortality (OR: } 32.6,95 \% \\
\text { CI: } 8.8-120.2 \text { ) }\end{array}$ \\
\hline Strbian et $\mathrm{al}^{19}$ & $\begin{array}{l}985 \text { Patients with } \\
\text { anterior IS }\end{array}$ & Intravenous thrombolysis & $\begin{array}{l}\text { Impact of symptomatic ICH on } \\
\text { mortality at } 3 \text { months }\end{array}$ & $\begin{array}{l}\text { According to different definitions used risk for } \\
\text { mortality ranged from } 1.5 \text { (95\% CI 1.0-2.2) } \\
\text { (any ICH) to } 4.8 \text { (95\% CI 2.8-8.2) (Safe } \\
\text { Implementation of Thrombolysis in Stroke } \\
\text { Registry) }\end{array}$ \\
\hline
\end{tabular}

Abbreviations: CI, confidence interval; ECASS, European Cooperative Acute Stroke Study; ICH, intracerebral hemorrhage; IS, ischemic stroke; OR, odds ratio; PH2, parenchymal hematoma type 2; RS, Rankin scale; tPA, tissue plasminogen activator. 
experienced $\mathrm{PH}$ have a 2-fold increased risk to die compared with those who did not.

Results from clinical trial on recombinant tissue plasminogen activator administration in patients with IS identified $\mathrm{PH}$ type 2 as significantly related to an increased risk of 3-month death. ${ }^{8,20}$ As a consequence, cerebral hematoma, either of primitive intracerebral hemorrhage or of HT of IS, seems to play a crucial role in mortality risk. Our study underlines this association even in patients treated with conservative therapy (not thrombolysis).

HT worsen prognosis in patients with IS. In particular, the occurrence of $\mathrm{PH}$ increases the risk of mortality even in patients not treated with thrombolytic agents.

\section{References}

1. Balami JS, Chen RL, Grunwald IQ, et al. Neurological complications of acute ischaemic stroke. Lancet Neurol 2011;10:357-371.

2. Feigin VL, Lawes CM, Bennett DA, et al. Worldwide stroke incidence and early case fatality reported in 56 population-based studies: a systematic review. Lancet Neurol 2009;8:355-369.

3. Wardlaw JM, Murray V, Berge E, et al. Thrombolysis for acute ischaemic stroke. Cochrane Database Syst Rev 2009;4:CD000213.

4. Hong KS, Kang DW, Koo JS, et al. Impact of neurological and medical complications on 3-month outcomes in acute ischaemic stroke. Eur J Neurol 2008;15:1324-1331.

5. Molina CA, Montaner J, Abilleira S, et al. Timing of spontaneous recanalization and risk of hemorrhagic transformation in acute cardioembolic stroke. Stroke 2001;32: 1079-1084.

6. England TJ, Bath PM, Sare GM, et al. Asymptomatic hemorrhagic transformation of infarction and its relationship with functional outcome and stroke subtype: assessment from the Tinzaparin in Acute Ischaemic Stroke Trial. Stroke 2010;41:2834-2839.

7. Toni D, Fiorelli M, Bastianello S, et al. Hemorrhagic transformation of brain infarct: predictability in the first 5 hours from stroke onset and influence on clinical outcome. Neurology 1996;46:341-345.

8. Fiorelli M, Bastianello S, von Kummer R, et al. Hemorrhagic transformation within 36 hours of a cerebral infarct: relationships with early clinical deterioration and 3-month outcome in the European Cooperative Acute Stroke Study I (ECASS I) cohort. Stroke 1999;30:2280-2284.

9. Terruso V, D'Amelio M, Di Benedetto N, et al. Frequency and determinants for hemorrhagic transformation of cerebral infarction. Neuroepidemiology 2009;33:261-265.

10. D'Amelio M, Terruso V, Famoso G, et al. Cholesterol levels and risk of hemorrhagic transformation after acute ischemic stroke. Cerebrovasc Dis 2011;32:234-238.

11. Pessin MS, Del Zoppo GJ, Estol CJ. Thrombolytic agents in the treatment of stroke. Clin Neuropharmacol 1990; 13:271-289.

12. Wolpert SM, Bruckmann H, Greenlee R, et al, for the rtPA Acute Stroke Study Group. Neuroradiologic evaluation of patients with acute stroke treated with rtPA. AJNR 1993;14:3-13.

13. Adams HP Jr, Bendixen BH, Kappelle LJ, et al. Classification of subtype of acute ischemic stroke. Definitions for use in a multicenter clinical trial. Stroke 1993;24: 35-41.

14. Brott T, Marler JR, Olinger CP, et al. Measurements of acute cerebral infarction: lesion size by computed tomography. Stroke 1989;20:871-875.

15. Jha P, Deboer D, Sykora K, et al. Characteristics and mortality outcomes of thrombolysis trial participants and nonparticipants: a population-based comparison. J Am Coll Cardiol 1996;27:1335-1342.

16. Heuschmann PU, Kolominsky-Rabas PL, Misselwitz B, et al, German Stroke Registers Study Group. Predictors of in-hospital mortality and attributable risks of death after ischemic stroke: the German Stroke Registers Study Group. Arch Intern Med 2004;164:1761-1768.

17. Bateman BT, Schumacher HC, Boden-Albala B, et al. Factors associated with in-hospital mortality after administration of thrombolysis in acute ischemic stroke patients: an analysis of the nationwide inpatient sample 1999 to 2002. Stroke 2006;37:440-446.

18. Paciaroni M, Agnelli G, Corea F, et al. Early hemorrhagic transformation of brain infarction: rate, predictive factors, and influence on clinical outcome: results of a prospective multicenter study. Stroke 2008;39: 2249-2256.

19. Strbian D, Sairanen T, Meretoja A, et al. Patient outcomes from symptomatic intracerebral hemorrhage after stroke thrombolysis. Neurology 2011;77:341-348.

20. Berger C, Fiorelli M, Steiner T, et al. Hemorrhagic transformation of ischemic brain tissue: asymptomatic or symptomatic? Stroke 2001;32:1330-1335.

21. Goldstein JN, Marrero M, Masrur S, et al. Management of thrombolysis-associated symptomatic intracerebral hemorrhage. Arch Neurol 2010;67:965-969. 